\title{
Enterprise Approach to Modelling of Risks in the Project Lifecycle of Naval Aviation Asset Ship Integration
}

\author{
Matthew $\mathrm{COOK}^{1}$ and John P.T. MO \\ RMIT University, Melbourne, Australia
}

\begin{abstract}
A strategic capability of contemporary naval ships is the ability to launch and recover embarked aircraft such as helicopters in a maritime environment. Such operations are enormously challenging due to deck motion, limited landing space, visibility, ship's superstructure, etc. This places extreme pressure on the pilot, ship's crew and the platforms alike, making such shipboard operations the most dangerous of all helicopter flight missions. Therefore, the design and integration of equipment, systems and aids to ensure such operations are done as safely as is practicably possible, presents ship builders, aircraft manufacturers, engineers and pilots with some extremely demanding and complex problems. Major naval ship design/build programmes that include an aviation capability, will inevitably need to engage resources across multiple disciplines that include, but not limited to; engineering, design, logistics, administration, procurement, legal, alliance partners and the customer to manage project risks from the outset. This research highlights the need for a holistic/Systems Engineering approach that recognises risks across the wider ship programme, that can only be managed/resolved by cross-discipline collaboration. This paper presents a novel methodology to elicit risks qualitatively and models the relative risk profile of an aviation project throughout the ship programme lifecycle. The use of an enterprise model based on the three ' $\mathrm{P}$ ' element methodology (3PE): Product, Process, People within an environment has been developed. Furthermore, the research outlines a continuous management and visualisation approach that enables a process of dynamic analysis to both reduce and/or mitigate residual risks progressively throughout the project lifecycle to acceptable levels.
\end{abstract}

Keywords. Aviation, Risk Identification, Risk Structure, Risk Management, Modelling Risks.

\section{Introduction}

For modern naval vessels it is essential that air support is part of the ship's operational capability. While dedicated aircraft carriers offer enough deck area for both fixed wing and rotary wing aircraft, it is only in the last fifty years, that the use of helicopters has seen this capability applied to ships as small as Offshore Patrol Vessels through to Frigates and Destroyers. The ability for such ships to operate these aircraft significantly increase the platforms capability and flexibility. This includes; improved warfighting capability, strategic reconnaissance, search \& rescue, replenishment at sea and personnel transfer.

\footnotetext{
${ }^{1}$ Corresponding Author, Email: s3315531@student.rmit.edu.au.
} 
While the value of an air capability is clear, such operations present enormous challenges for both the ship and aircraft platforms alike. Deck motion, limited landing space, visibility, ship's superstructure, spray, etc., make such shipboard operations the most dangerous of all helicopter flight missions. Therefore, the design and integration of equipment and technology that aims to ensure such operations are done as safely as is practicably possible, presents ship builders, aircraft manufacturers, engineers and pilots with some extremely demanding and complex problems.

The lifecycle of a complex platform, like a ship or aircraft, can last for decades, with each of the phases illustrated by Figure 1. In many cases, the same organisation may not retain ownership of the platform throughout the programme lifecycle. However, due to complexity of the engineering system and the intervention of change at different stages of the lifecycle, engineering systems are almost always designed, constructed and operated under unavoidable conditions of risk and uncertainty.

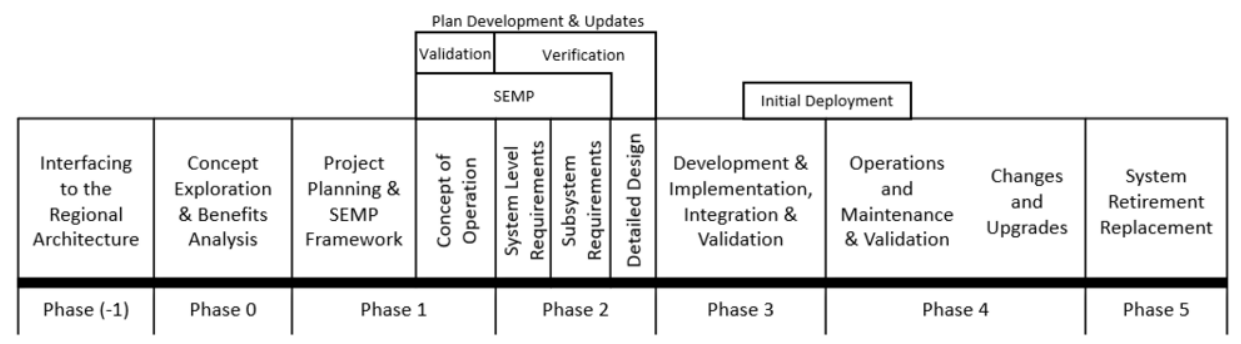

Figure 1. Typical Systems Engineering lifecycle showing phases of system development.

Hence, the level of risks can be affected significantly in different phases due to changes in alliance relationship, personnel, labour market technology advancement, asset ownership, etc. In Figure 1, risks have to be managed all the way from phase 1 to phase 5 , thus the approach to risk management must be consistent to ensure the same (and no less) level of certainty of continuity of business. However, the methodology to assess risks will need to be changed [1].

From the asset owner's perspective, the government prefers to secure a simple, no drama approach that mitigates all risks in the asset's lifecycle. Therefore, it is common practice for Governments to put a competitive tender contract to organisations and/or alliances for certain phases of the platform's lifecycle. As a result, organisations must be able to manage all risks in a consistent manner, i.e. risk levels and planned risk management strategy can be carried out in a reliable system's approach, and yet be able to provide an assessment of risks in all phases of the project lifecycle [2]. Unfortunately, due to changes in the lifecycle, many risks cannot be assessed in the same way as in different phases. For example, at phase 1 there is sparse and opaque engineering information about the asset. Assessment of the early phase risks has to be made using intuitive/speculative methods. Financial losses and schedule impacts are typically ballpark type estimates. By phase 3, all engineering information should have been completed and frozen. Risks in phase 4 are mainly aviation-oriented and span across aircraft, pilots, air traffic management, weather, component failure, flying hour, to name a few. Assessment of the later phases should include reliability data of equipment and historical data losses can be accurately calculated from accounting records. 
When an organisation or an alliance is awarded the contract to design and build a naval vessel, the inclusion, of an aviation capability will introduce many significant and complex risks that need to be addressed throughout the programme lifecycle. It is essential that a way of organising the risks is established to enable dynamic and ongoing control and mitigation. These risks require a holistic and consistent identification and management approach from the very earliest stages of the programme through to disposal of the asset to be adopted in order to produce a realistic and trustable lifecycle estimate.

This paper presents an enterprise architecture approach to the development of a lifecycle model for managing risks of naval projects. The project enterprise is modelled with 3PE methodology which presents a project enterprise in three hierarchical elements: product, process and people. Additional levels of derivation can be expanded as necessary. By evolving the architectural lifecycle over time and using the hierarchy of risks derived from the three fundamental enterprise architectural elements, it is then possible to estimate risks in different phases of the project.

\section{Literature review}

Complex defence engineering projects are usually coordinated by a technical process built on a backbone of Systems Engineering Methodology [3]. This process is generally structured to include several strategic mandatory stages and theoretical gates which need to be passed before the change can be progressed. An integral part of the Systems Engineering Methodology is Risk Management, see Figure 2.
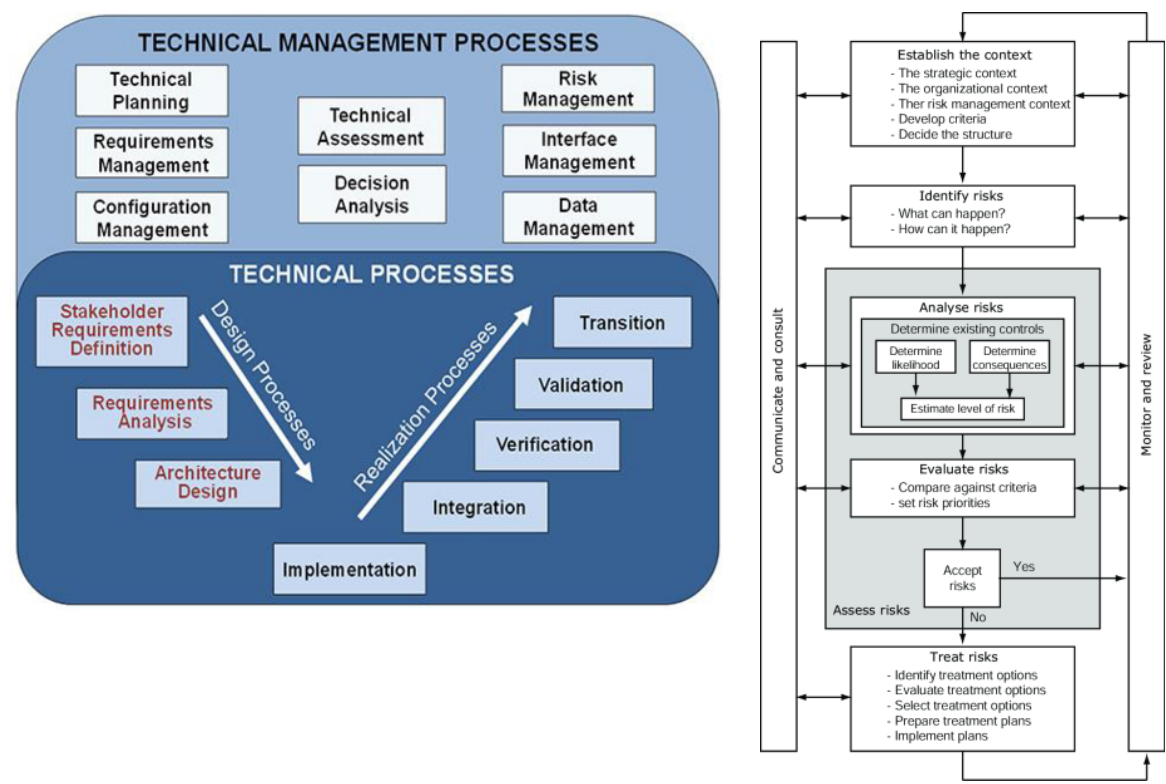

Figure 2. Systems Engineering Process and ISO31000 compliant Risk Management Framework.

This literature review examines past research in theories and practices of risk management throughout the whole engineering project lifecycle. The literature review has been divided into several sub-sections to focus our findings. 


\subsection{Enterprise architecture modelling and $3 P E$ modelling}

When faced with an extensive risk register that may been the result of several workshops and the collaboration of various resources, an early challenge is to systemically identify where the risks reside i.e. technical, resources, work practices, etc. Conventional risk analysis methods lack the ability to remove this opacity. A novel qualitative analysis approach is to employ the 3PE methodology [4]. By segmenting the enterprise into three major sectors, including the interactions between the segments, it should be possible to identify and even visualise where the majority of risks reside and more specifically what the key project risk drivers are and ultimately manage them throughout the life of the project, see Figure 3. The 3PE model is made up of three elements Product, People \& Process and essentially offers a useful way of sorting project risks by their nature. The map in Figure 3 highlights the relationship between the 3Ps within an environment (E) being the organisation This environment can be influenced by outside factors including political decisions, changes to policy, technology updates, etc.

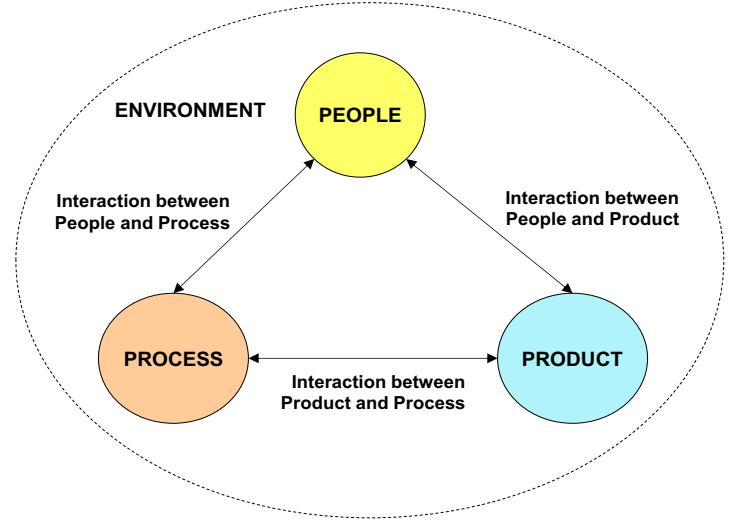

Figure 3. Product, Process, People \& Environment (3PE) model.

Modelling of risks associated with the 3Ps and their interactions can be logically represented by formulation of the $3 \mathrm{PE}$ for single enterprise model and has three interaction links. The risks associated with the individual 3P elements can be considered independent events that. Whereas, the interactions are examples of risks that are dependent and therefore influenced by either of the connected elements. All are affected by the environment.

Although initially this method will not highlight the individual key risk drivers, it will provide visibility of where the majority of risks reside, and which element and/or interaction are significantly impacting the programme. It should be noted that this is a dynamic process and will alter as the project moves through the lifecycle.

\subsection{Delphi style risk assessments}

For special stages of engineering lifecycle, impact is normally understood, the Delphi method is required to estimate the probability. Technically, the Delph method is a forecasting process framework based on the results of multiple rounds of questionnaires sent to a panel of experts. Several rounds of questionnaires are sent out to the group of experts, and the anonymous responses are aggregated and shared with the group after 
each round. The experts are allowed to adjust their answers in subsequent rounds, based on how they interpret the "group response" that has been provided to them. Since multiple rounds of questions are asked and the panel is told what the group thinks as a whole, the Delphi method seeks to reach the correct response through consensus [5]. Depending on the size of the project, this method can become overwhelming and very time consuming for large numbers of risks.

\subsection{Data driven risk assessments}

The concept of analysing probability of success to make project ranking decisions requires quantitative decision support methodologies. Componation \& Farrington [6] gave an overview of grid problem solving tools supporting continuous process improvement teams. Chakravorty [7] applied Benefit and Effort Analysis to prioritise system improvement projects for each project or action based on a weighted sum of factors considered relevant to the organisation. Reyes et al [8] investigated optimisation of software development using a genetic algorithm to propose a cost-effective investment of project resources to improve the probability of project success. The success probability output of the prediction model was evaluated relative to cost. Nicholds \& Mo [9] proposed a performance effectiveness function that took into account difficulty of project execution relative to resources available to the project to determine the prospects of optimisation. These researches showed a wide variety of quantitative tools have been used to monitor risks in engineering projects when information on its design, resources and development methods are generally clear.

\subsection{Summary and findings of literature review}

One of the core activities at the early stages of the process is risk identification and assessment. While it could be argued that risk assessment of the entire lifecycle at the project development stage may lack the full granularity of the data too adequately understand/address risk at the critical early stage. Risk management is a dynamic process that is evolving continuously over the programme life. Hence, adopting a consistent enterprise architecture can assist organisations to maintain a steady and reliable risk management process. In future work, this methodology will be further explored for managing Systemic risk described by Ellinas et al [10] as the exposure of a project to systemic risk varies in a non-trivial manner as it evolves, at both micro and macro level [10].

For this paper, it is important to acknowledge that there are essentially two defined areas of naval aviation risk. The first relates to the design and integration of aviation equipment into the holistic ship build. The second is the operational risk of flying aircraft (in this case naval helicopters). Although it is clear these two areas are interlinked i.e. ship born aviation equipment and systems helps to ensure helicopter operations are conducted safely. This research mainly focuses on the former area of design and installation of equipment and systems. 


\section{Project Enterprise Architecture Modelling}

This research attempts to offer an alternative approach to these challenges by proposing the use of several novel modelling methods. The general strategy, which is ubiquitous in risk analysis, is to split the modelling into an initial qualitative approach followed by a detailed quantitative analysis. This takes two steps:

1. Identify all risk in project lifecycle (qualitative); and

2. Assessment of the significance, and management/mitigation strategy (quantitative).

This paper will focus mainly on point one and will propose a qualitative modelling method that systematically sorts project risks into logical segments. This offers the distinct advantage of clearly identifying where the project risks reside so appropriate actions, funding, resources, etc. can be allocated. Although not fully detailed in this paper, some insight into methodology for point two is presented to ensure it is clear how the research presented in this paper links into the quantitative stage methodology.

\subsection{Lifecycle modelling using $3 P E$ approach}

Such an enterprise model can be used to describe the compiled risks into the risk register at the infancy of a project when time $t_{0}$. This can be thought of as the initial or baseline set of risks and is essentially a "snapshot" of the project risk the enterprise is carrying at $t_{0}$. The enterprise model enables dynamic updating between key milestones in the Systems Engineering Process over the lifecycle. By carefully analysing the effectiveness of mitigations, identification of trends and changes in the enterprise architecture the evolution of project risk can be mapped out from "snapshots" at $t_{n}$ to form an expected trajectory, as shown in Figure 4.

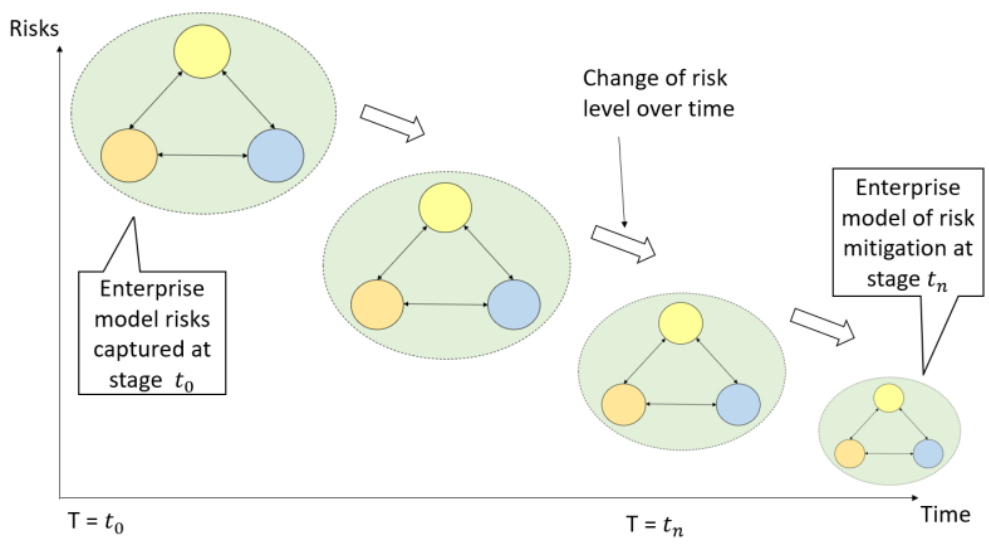

Figure 4. Expected change in risk over time.

Much of the work in the early phase of risk assessment deals with the risks that have been identified and populated into some form of register. It is essential that these risks are vetted to confirm they are genuine risks. Another challenge with extensively populated registers is risk duplication. This can occur due to specific wording of the risk and it is important to identify and eliminate risks that may be worded slightly differently but are essentially the same risk. 
When the project progresses to later phases, e.g. detail design or implementation, many of the previously uncertainty in systems or components will be confirmed and committed. For risks under Product category, it is normal that component or sub-system reliability estimates, are available for risk assessment [11] [12] [13]. Risk levels can then be assessed together with estimates of failure of the component or sub-system.

Likewise, operational processes of system, e.g. engineering processes in manufacturing, testing, etc. are determined through adaptation of standards and industry de facto codes of conduct. Risk of these processes can be obtained from similar past experiences or from industry wide statistics that are compiled by government bureaus or industry associations. In this case, since the process map can be drawn up readily, the probability of failure of the whole process can be estimated from normal decision tree methodologies [14].

Probability the most difficult estimate to be made in any engineering project is resource (people) reliability. Lee et al [15] proposed an analytical approach to quantify human process reliability. THERP (Technique for Human Error Rate Prediction) is probably the most widely used estimation method for human related risks [16] [17]. These methods require knowledge of the type of people involved in the work hence it is more logical to be used when qualification and experience of the people allocated to those parts of the project be clarified and understood.

\section{Case Study}

In mid-2018 a large defence industry organisation won the contract to design and build a new class of naval ship. Among the many capabilities defined by the customer, the ability to operate rotary wing aircraft from the platform was highlighted as a key requirement. To achieve this, the vessel would need to be designed with some obvious key features and several major pieces of aviation equipment including: an appropriately sized \& strengthened flight and hangar deck, helicopter landing \& traversing system, Visual Landing Aids, RADAR, Air Traffic Management System, maintenance capability, fuel system, power system, air weapons, air crew accommodation, etc. As described earlier, such a project will introduce a large number of significant and varied risks to the overall programme that will need to be managed by aviation, an appropriate discipline and/or the wider programme.

In Naval Aviation Squadron Risk Analysis, Robinson [18] acknowledges that the Naval Aviation flight mishap rate has declined over the last 60 years, but human error factors have stayed relatively constant at around $80 \%$. In order to better understand this, the authors of this research created a risk register to be completed at a workshop with key staff working in the Naval defence and aviation industry. The personnel involved included Engineers, Project Managers, Support Managers and several members of the Executive Team. The workshop was split into two sections, firstly a focused risk review to capture what were considered purely aviation risks. This was followed by a review of a wider risks that could impact the programme holistically and jeopardise overall success. The risk registered generated from this workshop was substantial with over three hundred risks identified relating to everything from technical challenges, communication issues, distance between partner firms, financial challenges, etc. 


\subsection{Applying 3P to identified Risks}

In order to make such a substantial risk register both clear and manageable to work with, analysis using the $3 \mathrm{P}$ methodology was undertaken by associating each risk with an element or interaction, as per the 3P methodology.

The significance of the 3Ps or the interactions can then be calculated and expressed in a percentage that can be visualised in Figure 5. It is not surprising that for a naval aviation focused design and integration project that both Product and Process are the major sources of risk. Furthermore, the interaction of People/Product is also significant and this again unsurprising given the nature of the project.

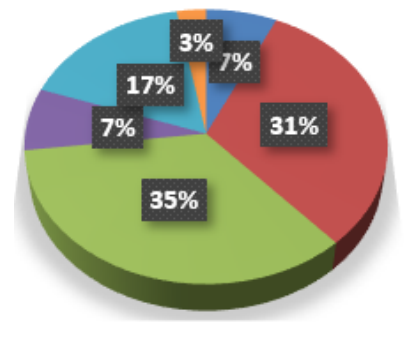

$$
\begin{aligned}
& \text { — People } \\
& \text { — Process } \\
& \text { n Product } \\
& \text { — Process/People } \\
& \text { — Process/Product } \\
& \text { - People/Product }
\end{aligned}
$$

Figure 5. Percentages of risks organised within 3P.

It is worth hypothesising that were this a services type project, then potentially People, Process and the interaction of People/Process would most likely be the more significant and dominant sector of risk.

\subsection{Risk assessments at early phases}

For each of the 3P's and interactions, an example of a risk has been selected to illustrate how the Delphi method risk assessment, see Figure 6.

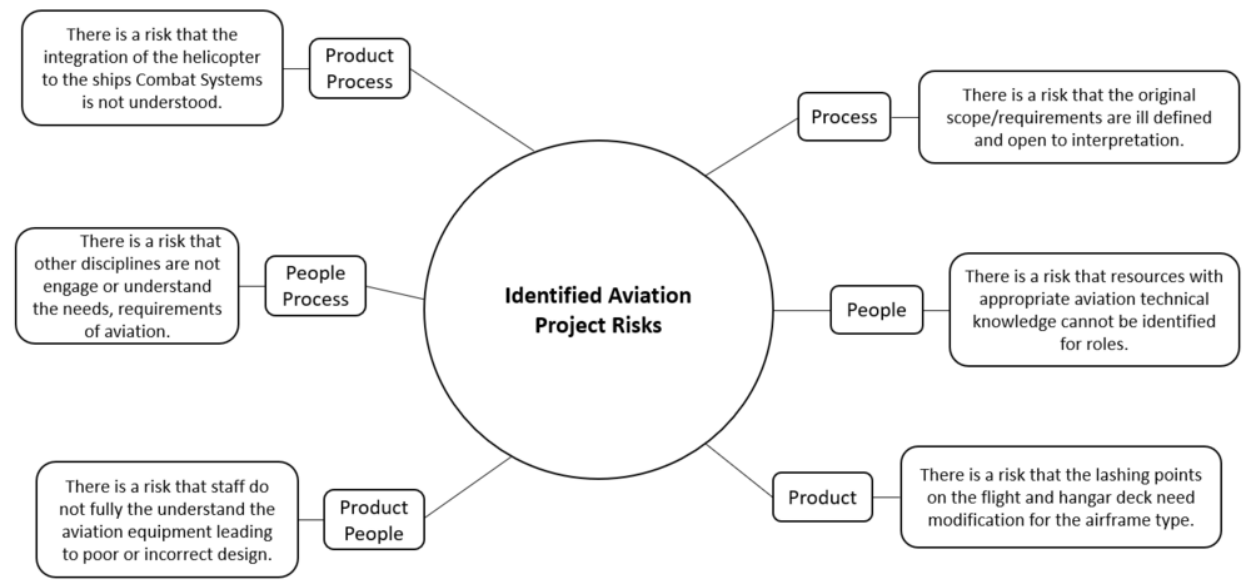

Figure 6. Identified Project Risks. 
This is just an example of each of the 3Ps as well as their dual interaction elements. There are obviously many more risk items as explained earlier. An estimate risk score for each risk was determined and this can be seen in Table 1.

Table 1. Risk for identified risks.

\begin{tabular}{|l|l|c|}
\hline \multicolumn{1}{|c|}{$\begin{array}{c}\text { 3PE } \\
\text { category }\end{array}$} & \multicolumn{1}{c|}{ Risk Identified } & $\begin{array}{c}\text { Risk Score } \\
\text { (1 to 5) }\end{array}$ \\
\hline Process & $\begin{array}{l}\text { There is a risk that the original scope/ requirements are ill defined and } \\
\text { open to interpretation. }\end{array}$ & 4.2 \\
\hline People & $\begin{array}{l}\text { There is a risk that resources with appropriate aviation technical } \\
\text { knowledge cannot be identified for roles. }\end{array}$ & 3.8 \\
\hline Product & $\begin{array}{l}\text { There is a risk that the lashing points on the flight do not fit the airframe } \\
\text { type. }\end{array}$ & 2.8 \\
\hline $\begin{array}{l}\text { People/ } \\
\text { Process }\end{array}$ & $\begin{array}{l}\text { There is a risk that the helicopter and its ships Combat Systems cannot be } \\
\text { integrated in design and operation. }\end{array}$ & 3.5 \\
\hline $\begin{array}{l}\text { People/ } \\
\text { Process }\end{array}$ & $\begin{array}{l}\text { There is a risk that other disciplines do not follow/ adopt the aviation } \\
\text { design and operation process. }\end{array}$ & 1.2 \\
\hline $\begin{array}{l}\text { Product/ } \\
\text { People }\end{array}$ & $\begin{array}{l}\text { There is a risk that staff do not understand operation requirements of the } \\
\text { aviation equipment leading to poor or incorrect design. }\end{array}$ & 4.8 \\
\hline
\end{tabular}

\subsection{Risk assessments at later phases}

While no such data is available for the case study at this stage, it would be useful to point out that the risk assessment system will continue to monitor the risk profile of this project. For the item in the Product category in Table 1, there are several choices of the lashing system design. The degree of unknown can change depending on the level of "militaryoff-the-shelf" components and type of airframe to be adapted in the system design at the detail design stage.

\section{Conclusion}

There is potentially an argument that while this 3P methodology highlights where risks reside by their nature, it does not identify the risks that are either the most significant or critical for the project. This can only be determined by either assessing the risk (likelihood vs consequence) and/or some form of weighting method. It is therefore theoretically possible that one of the segments or interactions that has a low percentage of associated risks may contain a critical risk that could have a major impact on project success.

Through this research to find a systematic methodology to assist engineers to manage risks in the project lifecycle, we have proposed and illustrated a new holistic approach and corresponding risk assessment methods in different phases of a project lifecycle. As more information is accumulated for the project, the risks are either eliminated, reduced or re-calculated. Although some risks may go up due to new circumstances evolving from executing the project, most risks are reduced and thus the summation of the risks should eventually be lowered in the project lifecycle. 


\section{References}

[1] M. Cook, J.P.T. Mo, Strategic risk analysis of complex engineering system upgrades, European Scientific Journal, October 2015, SPECIAL edition Vol. 2, pp. 64-80

[2] BS ISO 31000:2018 - Risk management. Guidelines, ISO, 2018.

[3] K. Kosanke and J.G. Nell, Standardisation in ISO for enterprise engineering and integration, Computers in Industry, 1999, Vol. 40, pp. 311-319.

[4] M. Cook and J.P.T. Mo, A systems approach to life cycle risk prediction for complex engineering projects, Cogent Engineering, 2018, Vol.5, Issue 1, No.1451289, DOI: https://doi.org/10.1080/23311916.2018.1451289

[5] I. Kıral, Z. Kural and S. Çomu, Risk Identification in Construction Projects: Using the Delphi Method. The $11^{\text {th }}$ International Congress on Advances in Civil Engineering (ACE2014), 21-24 October 2014, Istanbul.

[6] P.J. Componation and P.A. Farrington, Identification of effective program-solving tools to support continuous process improvement teams, Engineering Management Journal, 2006, Vol. 12, No. 1, pp. 23-29.

[7] S.S. Chakravorty, Prioritizing Improvement Projects: Benefit \& Effort (B\&E) Analysis, The Quality Management Journal, 2012, Vol. 19, No. 1, pp. 24-33.

[8] F. Reyes, N. Cerpa, A. Candia-Véjar and M. Bardeen, The optimization of success probability for software projects using genetic algorithms, Journal of Systems and Software, 2011, Vol. 84, No. 5, pp. 775-785.

[9] B.A. Nicholds and J.P.T. Mo, Risk assessment for aviation operations improvement projects, Journal of Aerospace Operations, 2016, Vol.4, pp. 31-48, DOI 10.3233/AOP-160057.

[10] C. Ellinas, N. Allan and A. Johansson, Project systemic risk: Application examples of a network model, International Journal of Production Economics, 2016, Vol.182, December 2016, pp. 50-62.

[11] A. Adamyan and D. He, System failure analysis through counters of petrinetpertinent models, Quality and Reliability Engineering International, 2004, Vol. 20, No. 4, pp. 317-335.

[12] S. Aksu, S. Aksu and O. Turan, Reliability and availability of pod propulsion system, Quality and Reliability Engineering International, 2006, Vol. 22, pp. 41-58.

[13] A.S.B. Tam and I. Gordon, Clarification of Failure Terminology by Examining a Generic Failure Development Process, International Journal of Engineering Business Management, 2009, Vol. 1, No. 1, pp. 33-36.

[14] J. Gingele, S.J. Childe and M.E. Miles, A modelling technique for re-engineering business processes controlled by ISO 9001, Computers in Industry, 2002, Vol. 49, pp. 235-251.

[15] S.J. Lee, M.C. Kim and P.H. Seong, An analytical approach to quantitative effect estimation of operation advisory system based on human cognitive process using the Bayesian belief network, Reliability Engineering and System Safety, 2008, Vol. 93, No. 4, pp. 567-577.

[16] P. Mahendra and A.J. Gaikwad, Human error probability estimation by coupling simulator data and deterministic analysis, Progress in Nuclear Energy, 2015, Vol. 81, pp. 22-29.

[17] M. Karthick, C.S. Kumar and T.P. Robert, BAYES-HEP: Bayesian belief networks for estimation of human error probability, Life Cycle Reliability and Safety Engineering, 2017, Vol. 6, No. 3, pp. 187-197.

[18] H.M. Robinson, Naval Aviation Squadron Risk Analysis Predictive Bayesian Network Modeling Using Maintenance Climate Assessment Survey Results, PhD thesis, Department of Modelling Simulation and Visual Engineering, Old Dominion University, Winter, 2014. 